\title{
Comparison of fatty acids, cholesterol, fat soluble vitamins and carotenoids content of skin and edible tissue of farmed African catfish (Clarias gariepinus, Burchell 1822)
}

\author{
Albena MERDZHANOVA, ${ }^{*}$ Diana A. DOBREVA, and Veselina PANAYOTOVA \\ Department of Chemistry, Medical University of Varna, Varna, 9002, Bulgaria
}

\begin{abstract}
African catfish (Clarias gariepinus) is new species for the Bulgarian market. It is a valuable source of biologically active components that play an important role in human diet, but there is lack of information for the quality of its dietary lipids. This study focuses on the assessment of skin and edible tissue lipid quality of farmed African catfish based on lipid content and detailed fatty acids, fat-soluble vitamins, cholesterol and carotenoids composition. Fatty acid composition was determined by gas chromatography with mass spectrometer (GC/MS) after lipid extraction. Vitamins $\mathrm{A}, \mathrm{D}_{3}$ and $\mathrm{E}$, beta-carotene, astaxanthin and cholesterol were analyzed simultaneously using high performance liquid chromatography (HPLC) with ultraviolet and fluorescence detectors. Lipids, cholesterol, astaxanthin and monounsaturated fatty acids (MUFA) were significantly higher in skin, whereas vitamin A and E, polyunsaturated fatty acids (PUFA) were higher in muscle tissue. Vitamin $\mathrm{D}_{3}$ showed comparable amounts in both tissues. Eicosapentaenoic acid (C20:5n3) and docosahexaenoic acid (C22:6n3) which are important indicators for fish lipids quality presented significantly high amounts. A portion of $100 \mathrm{~g}$ filet without skin contains approximately $600 \mathrm{mg}$. Results confirmed that African catfish meat - with or without the skin, can be valuable and preferable source of biologically active lipids.
\end{abstract}

Keywords: African catfish, fatty acids, vitamins, cholesterol, carotenoids

\section{Introduction}

According to FAO [1] and FAO-FISHSTAT [2] more than $40 \%$ of consumed fish come from farming. Many studies are focused on the importance of fish as protein source but also discuss its importance as valuable source of essential long chain fatty acids, fat soluble vitamins and pigments [3]. In addition, the benefits of fish consumption for vulnerable groups are also well recognized and due to these facts, there is a growing interest in new aquaculture fish species for our country. Moreover, fish skin is a valuable byproduct and is currently used as a component in animal and fish feed.

One of the most consumed farmed freshwater fish in the world is Silurid (catfish), with about 2200 species distributed in 38 families. The most commercially important is Channel catfish (Ichtalurus glanis), South Asian (Pangasius pangasius) and African catfish (Clarias gariepinus). These species have short production cycle and tolerance to high cultivation densities [4]. In recent years consumptions of Channel catfish and African catfish in some Central and Eastern European countries have increased. The most recent information about the current state of Bulgarian freshwater species showed tendency of farming new fish species such as North African catfish (Clarias gariepinus, Burchell, 1822) as interesting species with high potential for fish farming [5]. Although the importance of these species, only limited investigations on nutritional composition on Silurid species as channel catfish were carried out [6].

Until now, there is no information concerning fatty acid (FA) composition, cholesterol, fat soluble vitamins and carotenoids in African catfish skin and muscle from Bulgarian market available in the literature. Most of the studies of fish skin are focused mainly on the protein composition, while research on its lipids is scarce. Due to described facts, the objective of the present study was to evaluate the biologically active lipid compounds listed above in farmed African catfish (Clarias gariepinus) skin and edible tissue from Bulgaria.

\section{Experimental}

\subsection{Sample collection}

Samples were obtained from Varna fish market during May 2016. African catfish were raised in a fish farm (Panagyurishte, region Pazardshik), where fish is fed on commercial feed mixtures. Each specimen was filleted - muscle tissue was separated from the skin with a knife. Two replicate samples were prepared. 


\subsection{Fatty acids analysis}

Lipid extraction: Five grams of raw homogenized tissue were subjected to Bligh and Dyer extraction method [7]. Total lipids (TL) were determined gravimetrically and expressed as $\mathrm{g}$ per $100 \mathrm{~g}$ wet weight $\left(\mathrm{g} \cdot 100 \mathrm{~g}^{-1}\right.$ w.w.).

Preparation of FA methyl esters: The dry residue of the chloroform fraction was methylated by acidcatalyzed transmethylation using $2 \% \quad \mathrm{H}_{2} \mathrm{SO}_{4}$ in methanol and $n$-hexane [8]. After centrifugation (3500 rps), the hexane layer was separated and analyzed by gas chromatography with mass detector (GC-MS).

GS-MS analysis: The combined hexane layers were analyzed by gas chromatography. Thermo Scientific FOCUS Gas Chromatograph was equipped with TR-5 MS capillary column (30 m, $0.25 \mathrm{~mm}$ i.d.). Polaris Q Mass detector was used for peaks identification. FAME mix standard (SUPELCO 37 F.A.M.E. Mix C4 - C24) and internal Data Base (Thermo Sciences Mass Library, USA) was used for identification and quantification of fatty acid methyl esters. Results are expressed as a relative percentage of each FA of the total FA [9]. All chemicals were of analytical and GC grade.

\subsection{Fat soluble vitamins, pigments and cholesterol analysis}

Saponification and extraction: Skin and fillet samples were homogenized and used for determination of alltrans-retinol, ergocalciferol, cholecalciferol, alphatocopherol, $\beta$-carotene, astaxanthin and cholesterol contents. Sample preparation procedure was done by the method of Dobreva et al. [10]. Approximately one gram homogenate $(1.000 \pm 0.005 \mathrm{~g})$ was placed into a glass tube with a screw cap. $1 \%$ w/v solution of $\mathrm{L}$ ascorbic acid (in methanol) and $0.5 \mathrm{M}$ potassium hydroxide in methanol were added. Samples were incubated at $50^{\circ} \mathrm{C}$ for $30 \mathrm{~min}$. After the test tubes were cooled analytes were extracted twice with a solution of $n$-hexane:dichloromethane $=2: 1(\mathrm{v} / \mathrm{v})$. The combined extracts were evaporated, redissolved in methanol:dichloromethane solution, and filtrated ( $0.45 \mu \mathrm{m}$ syringe filter). A volume of $20 \mu \mathrm{l}$ samples were injected into the high-performance liquid chromatography (HPLC) system.

HPLC analysis: The chromatographic analysis was performed on HPLC system (Thermo Scientific Spectra SYSTEM) equipped with ultraviolet (UV2000) and fluorescence (FL3000) detectors. Alltrans-retinol, ergocalciferol, cholecalciferol, alphatocopherol, $\beta$-carotene, astaxanthin and cholesterol were determined simultaneously using HPLC/UV/FL system equipped with RP analytical column Synergi $4 \mu$ Hydro-RP $80 \mathrm{~A}$ pore $250 \times 4.6 \mathrm{~mm}$, through a mobile phase 75:20:5 = acetonitrile: methanol: 2propanol (ACN: $\mathrm{MeOH}: i-\mathrm{PrOH}$ ), at $1.1 \mathrm{~mL} / \mathrm{min}$. Detection of ergocalciferol $(\lambda=265 \mathrm{~nm})$, cholecalciferol $(\lambda=265 \mathrm{~nm}), \beta$-carotene $(\lambda=450$ $\mathrm{nm})$, astaxanthin $(\lambda=474 \mathrm{~nm})$ and cholesterol $(\lambda=$
$208 \mathrm{~nm})$ was performed by UV detector. Concentrations of all-trans-retinol (at $\lambda \mathrm{ex}=334 \mathrm{~nm}$ and $\lambda \mathrm{em}=460 \mathrm{~nm}$ ) and $\alpha$-tocopherol (at $\lambda$ ex $=288$ $\mathrm{nm}$ and $\lambda \mathrm{em}=332 \mathrm{~nm}$ ) were measured by fluorescence detection.

\subsection{Nutrition quality indices (NQI)}

Nutrition qualities are estimated by several indices and ratios based on FA composition: the indices of atherogenicity (AI), thrombogenicity (TI), cholesterolemic index $(\mathrm{h} / \mathrm{H})$; PUFA/SFA and n6/n3 ratios, according to Simopolous [11]. Ulbritcth and Southgate [12] presented two indices - AI and TI, that could be better characterize the atherogenic, and thrombogenic potential of unsaturated FA. h/H presents the functional effects of different PUFAs of cholesterol metabolism (hypo- and hypercholesterolemic effect), and calculated according to Santos-Silva et al. [13]. To evaluate the fish lipid consumption influence on serum cholesterol levels, cholesterol/SFA index (CSI) was calculated according to Connor et al. [14].

\subsection{Statistical analysis}

The results were calculated as a mean and standard deviation (mean \pm SD). Graph Pad Prism 6.0 software is used for analyzing the obtained data. An unpaired $t$-test statistical analysis was applied to estimate the differences between the analyzed samples. The comparison was made for total lipids, fat soluble vitamins, cholesterol and beta-carotene and individual fatty acid and fatty acid groups. The differences were considered significant at $p<0.05$.

\section{Results and discussion}

\subsection{Total lipid and fatty acid composition}

The lipid content and fatty acid composition in Silurid species (as Channel and hybrid catfish) skin are poorly documented [15]. Most research is focused on muscle tissue lipid and FA composition of the species $[16,17]$. Only one investigation of African catfish skin presented a limited data for its fatty acid profile [18]. In this study the total lipid (TL) content in the skin $\left(8.6 \pm 0.55 \mathrm{~g} \cdot 100^{-1} \mathrm{~g} \mathrm{w}\right.$.w.) was found two times higher than in the edible tissue $\left(3.7 \pm 0.23 \mathrm{~g} \cdot 100^{-1} \mathrm{~g}\right.$ w.w.). The difference in mean values between both tissues was significant $(p<0.001)$. These findings show that lipids are cumulated mainly in skin of African catfish compared to muscle tissue. Therefore, a common practice to reduce the fat intake is to remove the skin from fish fillets. Previously investigations presented similar results for trout species. Reboléa et al. [19] and Dobreva et al. [20] reported significantly higher skin TL compared to edible tissue in aquaculture rainbow trout from Granada, Spain and Dospat Dam Lake, Bulgaria. Recent study investigated fatty acid composition of the skin of four marine fish species [21]. Authors concluded that the different FA groups as saturated (SFA), monounsaturated (MUFA) and 
polyunsaturated FA (PUFA) a variable depending of fish species. In addition to fish muscle, fish skin is also important source of unsaturated FAs and this statement is well illustrated in our findings. Unsaturated FAs are near $68 \%$ of total FAs in African catfish skin TLs (See Table 1).

Table 1. FA composition of total lipids in the skin and muscle from farmed African catfish

\begin{tabular}{|c|c|c|}
\hline $\begin{array}{c}\text { Fatty acids } \\
(\% \text { of total FA })\end{array}$ & Skin & Tissue \\
\hline $6: 0$ & $0.73 \pm 0.02$ & $2.26 \pm 0.10$ \\
\hline $8: 0$ & $0.53 \pm 0.01$ & $2.35 \pm 0.14$ \\
\hline 10:0 & $0.68 \pm 0.02$ & $0.73 \pm 0.03$ \\
\hline $12: 0$ & $0.78 \pm 0.03$ & $1.35 \pm 0.23^{b}$ \\
\hline 14:0 & $1.00 \pm 0.04$ & $2.81 \pm 0.25^{\mathrm{a}}$ \\
\hline 16:0 & $19.98 \pm 0.80$ & $22.11 \pm 1.15^{b}$ \\
\hline 18:0 & $7.71 \pm 0.25$ & $4.54 \pm 0.45^{\mathrm{a}}$ \\
\hline $20: 0$ & $0.22 \pm 0.01$ & $0.50 \pm 0.03$ \\
\hline $21: 0$ & $0.13 \pm 0.01$ & $0.21 \pm 0.01$ \\
\hline $22: 0$ & $0.18 \pm 0.02$ & $0.64 \pm 0.02$ \\
\hline $23: 0$ & $0.15 \pm 0.01$ & nd \\
\hline $24: 0$ & $0.27 \pm 0.02$ & $1.23 \pm 0.10^{\mathrm{a}}$ \\
\hline SFA & 32.36 & $38.78^{a}$ \\
\hline $14: \ln 5$ & $0.45 \pm 0.02$ & $1.55 \pm 0.12^{\mathrm{a}}$ \\
\hline $16: \ln 7$ & $2.95 \pm 0.07$ & $2.85 \pm 0.20$ \\
\hline $18: \ln 9$ & $31.12 \pm 2.10$ & $2.68 \pm 0.18^{\mathrm{a}}$ \\
\hline $20: \ln 9$ & $0.07 \pm 0.01$ & nd \\
\hline $22: \ln -11$ & $0.93 \pm 0.03$ & $1.17 \pm 0.10^{b}$ \\
\hline $24: \ln 9$ & nd & $2.00 \pm 0.14$ \\
\hline MUFA & 35.52 & $10.25^{\mathrm{a}}$ \\
\hline $18: 3 n 6$ & $0.88 \pm 0.04$ & $1.77 \pm 0.45^{\mathrm{a}}$ \\
\hline $18: 3 n 3$ & $1.88 \pm 0.10$ & $3.82 \pm 0.64^{\mathrm{a}}$ \\
\hline $18: 2 n 6$ & $12.00 \pm 0.80$ & $20.26 \pm 1.25^{\mathrm{a}}$ \\
\hline $20: 5 n 3$ & $6.95 \pm 0.50$ & $2.50 \pm 0.30^{\mathrm{a}}$ \\
\hline $20: 4 n 6$ & $3.90 \pm 0.35$ & $0.10 \pm 0.01^{\mathrm{a}}$ \\
\hline $20: 3 n 6$ & $1.98 \pm 0.28$ & $2.40 \pm 0.15^{b}$ \\
\hline $20: 3 n 3$ & $0.46 \pm 0.03$ & $3.13 \pm 0.30^{\mathrm{a}}$ \\
\hline $20: 2 n 6$ & $0.36 \pm 0.01$ & $0.69 \pm 0.03$ \\
\hline $22: 6 n 3$ & $3.00 \pm 0.30$ & $14.87 \pm 0.86^{\mathrm{a}}$ \\
\hline $22: 2 n 6$ & $0.77 \pm 0.02$ & $1.00 \pm 0.08^{\mathrm{c}}$ \\
\hline PUFA & 32.18 & $50.54^{\mathrm{a}}$ \\
\hline$n 3$ & 12.29 & $24.32^{\mathrm{a}}$ \\
\hline$n 6$ & 19.89 & $26.22^{\mathrm{a}}$ \\
\hline
\end{tabular}

${ }^{\mathrm{a}} p<0.001,{ }^{\mathrm{b}} p<0.01$ and ${ }^{\mathrm{c}} p<0.05$; nd-not detected

Presented results showed different FA distribution in muscle tissue: $\mathrm{PUFA}>\mathrm{SFA}>\mathrm{MUFA}$ compared to skin tissue: MUFA $>$ SFA $\geq$ PUFA. Moreover, the content of FAs varied significantly within the analyzed tissues. Higher values of SFAs $(p<0.001)$ was noted in muscle, whereas skin contained more MUFAs and less PUFAs $(p<0.001)$. The major saturates in the skin and muscle were $\mathrm{C} 16: 0$ and C18:0 acids. Palmitic acid (C16:0) content was significantly higher in the muscle $(p<0.001)$, whereas C18:0 showed opposite trends and reached up to $7.7 \%$ in the skin. Large differences were observed for oleic acid (C18:1n9) values, which presented $87 \%$ of total MUFAs in skin, whereas in tissue, the same FAs was only $2.68 \%$ (26\% of total MUFAs). Higher levels of oleic acids were reported for culture African catfish muscle (32\%) from Nigeria [17], whereas lower values of C18:1n9 (25.3\%) were found for freshwater catfish from Polish fish markets [16]. Habib and Sakar [18] found similar high content of oleic acid in the skin of African catfish from Bangladesh. In this study most significant differences were found for PUFA levels $(p<0.001)$ of both tissues. The higher values of PUFAs (over that $50 \%$ of total FAs) in muscle tissue are due to greater amounts of linoleic (C18:2n6, LA) and docosahexaenoic acids (C22:6n3, DHA) compared to skin tissue. One possible reason for the high content of LA observed may be its commercial fish diet which is rich of this FA. On the other hand, LA is necessary to retain fish skin permeability, because epidermal cell membranes should be more fluid to facilitate transport. In contrast, the physiologically important PUFAs as eicosapentaenoic (C20:5n3, EPA) and arachidonic (C20:4n6, ARA) acids were two times higher in skin tissue. Our finding is in agreement with Chapkin et al. [22] statement, who supposed that arachidonic acid is abundant PUFA in the skin, as a structural component of phospholipids. This FA can be hydrolyzed from phospholipids by specific enzyme and serve as the major source of important epidermal eicosanoids, potent mediators of the inflammatory response. According to Weaver et al. [23] there is a correlation between (SFA+MUFA)/PUFA ratios, atherosclerosis progression and increase risk of cardiovascular diseases. Authors reported significantly higher values for this ratio (over than 4) for farmed catfish from Central America region. A discrepancy of these finding was determined for the FA profile of both analyzed tissues of Bulgarian African catfish, which had favorable ratios: 2.11 (skin) and 0.77 (muscle) that confirm good anti-atherosclerotic properties of catfish lipids.

The amounts of omega-3 (n3) and omega-6 (n6) PUFAs are often reported when assessing the health benefits of fish meat. In this study $\mathrm{C}_{18} \mathrm{n} 3$ and $\mathrm{n} 6$ PUFAs were found in low levels in skin tissues. In the human body these FAs a poorly converted to very long chain PUFAs (VLPUFA) $\mathrm{C}_{20}$ and $\mathrm{C}_{22} . \mathrm{C}_{20}$ and $\mathrm{C}_{22} \mathrm{n} 3$ and n6 VLPUFAs are probably responsible for major biological activities related to fish lipids. Consequently, determining contents of these VLPUFAs is important when considering the health effects of FAs in analyzed African catfish. In addition, the ratio of ARA to EPA, which are primary substrate for $\mathrm{C}_{20} \mathrm{n} 3$ and $\mathrm{n} 6$ eicosanoids can be used for evaluation of nutrition quality of fish lipids. In this work ARA: EPA ratios in skin (0.56) and muscle (0.10) tissues were below 1 and this confirms good quality of catfish lipids. In contrast, Weaver et al. [23] reported significantly high ARA: EPA ratios (11:1) in 
muscle lipids of farmed catfish from Central America, due to 20 times higher ARA than EPA levels. In this study the good lipid quality of muscle tissue is well illustrated by the balanced $n 3$ and n6 PUFAs content. In the skin n6 series PUFAs prevailed. Furthermore, fish utilize all types of FAs in various tissues for a number of specific physiological purposes, including maintenance of the structural integrity and viscosity of cell membranes, or as energy reserves for growth. Thus the observed differences in FA profile found in both analyzed tissues can be explained.

\subsection{Fat soluble vitamins, cholesterol and carotenoids contents}

The results for fat soluble vitamins, cholesterol and carotenoids are presented as average and standard deviation (mean $\pm \mathrm{SD}$ ). Data are expressed as microgram per 100 grams wet weight $\left(\mu \mathrm{g} \cdot 100^{-1} \mathrm{~g}\right.$ w.w.) for fat soluble vitamins (A, $\mathrm{D}_{3}$ and $\left.\mathrm{E}\right)$ and as milligram per 100 grams wet weight $\left(\mathrm{mg} \cdot 100 \mathrm{~g}^{-1}\right.$ w.w.) for cholesterol, astaxanthin and beta-carotene (Table 2).

Table 2. Fat soluble vitamins, cholesterol, carotenoids in skin and edible African catfish tissue $($ mean $\pm \mathrm{SD})$

\begin{tabular}{|l|l|c|}
\hline \multicolumn{3}{|c|}{ African catfish } \\
\hline & \multicolumn{1}{|c|}{ skin } & muscle \\
\hline $\begin{array}{l}\text { Cholesterol } \\
\left(\mathrm{mg} \cdot 100^{-1} \mathrm{~g}\right)\end{array}$ & $38.00 \pm 1.50$ & $10.63 \pm 0.48^{\mathrm{a}}$ \\
\hline $\begin{array}{l}\text { Astaxanthin } \\
\left(\mu \mathrm{g} \cdot 100^{-1} \mathrm{~g}\right)\end{array}$ & $66.33 \pm 2.10$ & $25.68 \pm 0.86^{\mathrm{a}}$ \\
\hline $\begin{array}{l}\text { Beta- } \\
\text { carotene } \\
\left(\mu \mathrm{g} \cdot 100^{-1} \mathrm{~g}\right)\end{array}$ & $24.62 \pm 0.95$ & $130.78 \pm 3.57^{\mathrm{a}}$ \\
\hline $\begin{array}{l}\text { Vitamin } \mathrm{D}_{3} \\
\left(\mu \mathrm{g} \cdot 100^{-1} \mathrm{~g}\right)\end{array}$ & $33.56 \pm 1.10$ & $34.26 \pm 1.24$ \\
\hline $\begin{array}{l}\text { Vitamin A } \\
\left(\mu \mathrm{g} \cdot 100^{-1} \mathrm{~g}\right)\end{array}$ & $49.78 \pm 0.97$ & $56.01 \pm 2.23^{\mathrm{b}}$ \\
\hline $\begin{array}{l}\text { Vitamin } \mathrm{E} \\
\left(\mu \mathrm{g} \cdot 100^{-1} \mathrm{~g}\right)\end{array}$ & $5500.00 \pm 123.5$ & $24000.13 \pm 348.7^{\mathrm{a}}$ \\
\hline
\end{tabular}

${ }^{\mathrm{a}} p<0.001,{ }^{\mathrm{b}} p<0.01$, and ${ }^{\mathrm{c}} p<0.05$

Vitamin E and carotenoids (astaxanthin and betacarotene) are important compounds with high antioxidant activity. In present study significant differences in analyte contents between analyzed tissues were observed. In both tissues, vitamin $\mathrm{E}$ was found in high quantity, and one possible reason is African catfish artificial diet as well as the necessity of higher degree of PUFAs antioxidant protection.

In presented study, this statement is well correlated with observed data: four times higher vitamin E content - two times higher PUFA content in muscle tissue, compared to skin lipids. An earlier study of farmed rainbow trout from Bulgaria also presented again that both tissues contained high values of vitamin $\mathrm{E}$, and significantly low levels of vitamin A. Similarly high quantity of vitamin D determined in both tissues $(200 \%$ of recommended daily intake, RDI) confirms good skin and muscle lipid quality of this fish species. The same study showed a similar correlation: higher vitamin E higher PUFA content [20].

Vitamin $\mathrm{D}_{3}$ content in skin and muscle of catfish is more than two times higher than recommended for daily intake of this vitamin in Bulgaria [24]. Thus, this species can be classified as excellent source of vitamin $\mathrm{D}_{3}$, which increased its nutritional value.

Cholesterol content varied significantly $(p<$ 0.001 ) between skin and muscle tissues. The higher values were found in skin, whereas in muscle its levels were three times lower. These findings characterize African catfish as suitable fish species for beneficial and healthy diet. Rosa et al. [25] reported similar results for cholesterol content (11.4 $\mathrm{mg} \cdot 100^{-1} \mathrm{~g}$ w.w.) of African catfish muscle tissue, whereas Dobreva et al. [20] found two times higher cholesterol (66 mg.100-1 $\mathrm{g}$ w.w.) in skin and four times higher in muscle $\left(46 \mathrm{mg} \cdot 100^{-1} \mathrm{~g} \mathrm{w}\right.$.w.) of rainbow trout species.

According to Kelestemir and Coban [26] the absorption of beta-carotene is varies in different tissues, but the main tissues in which carotenoids can be stored is the muscle tissue. This statement is confirmed by the presented results, where skin betacarotene content is five times lower compared to muscle tissue. In additions, beta-carotene has essential functions for fish growth and health, but fishes cannot synthesize it and thus must be supplemented by the diet. Comparable results for astaxanthin content of skin and muscle tissues of African catfish could not be found in the scientific literature.

3.3. Assessment of nutritional and functional quality of African catfish skin and muscle lipids

Comparative indicators used for relative nutritional and functional quality of fish lipids are n6/n3 and PUFA/SFA ratios (See Table 3). Calculated ratios varied significantly between analyzed tissues. Although n6/n3 values were higher in skin, this tissue contained more balanced PUFA/SFA ratios compared to muscle tissue. To preventing coronary heart disease, the decrease of dietary $n 6 / n 3$ ratio is the main advice and thus can be provoke decrease of plasma lipids and the risk of metabolite diseases respectively. Simopolous [11] assume that the beneficial n6/n3 ratio for the human health is lower or equal to 1.0. Our findings for this ratio (1.08-1.69) are in agreement with data in the literature $[15,17,27]$ and confirmed the good nutrition quality of both- skin and muscle lipids on African catfish.

In our study, the PUFA/SFA ratio was between 1.0 and 1.3, which is in recommended amount by the Department of Health [28]. Based on the reported ratio values, we may assume that both tissues of aquaculture African catfish from Bulgaria have are beneficial and well-balanced fatty acid composition. 
Table 3. Fatty acid contents, FA ratios, nutrition quality indices in African catfish skin and muscle tissue (mean $\pm \mathrm{SD})$

\begin{tabular}{|c|c|c|}
\hline \multicolumn{3}{|c|}{ African catfish } \\
\hline & skin & muscle \\
\hline$n 6 / n 3$ & 1.69 & $1.08^{\mathrm{b}}$ \\
\hline PUFA/SFA & 1.00 & $1.30^{\mathrm{a}}$ \\
\hline$E P A\left(m g \cdot 100^{-1} g\right.$ w.w. $)$ & $549.0 \pm 10.2$ & $75.0 \pm 5.0^{\mathrm{a}}$ \\
\hline$D H A\left(m g \cdot 100^{-1} g\right.$ w.w. $)$ & $237.0 \pm 5.5$ & $446.0 \pm 8.5^{\mathrm{a}}$ \\
\hline$E P A+D H A$ & 786.0 & 521.0 \\
\hline$A I^{*}$ & 0.40 & 0.53 \\
\hline$T I^{*}$ & 0.44 & 0.31 \\
\hline$h / H^{*}$ & 2.91 & 2.07 \\
\hline CSI* & 4.45 & $1.73^{\mathrm{a}}$ \\
\hline$m g$ vit. E/g PUFA & 2.16 & $15.27^{\mathrm{a}}$ \\
\hline $\begin{array}{l}* A I=[(C 12: 0+(4 \times C \\
n 3 P U F A+M U F A) ; \\
* T I=(C 14: 0+C 16: 0+ \\
P U F A)+(3 n 3 P U F A)+(n \\
* h / H=(C 18: 1 n 9+C 18 \\
C 20: 5 n 3+C 22: 6 n 3) /(C 1 \\
* C S I=(1.01 x S F A g \cdot 100 \\
\left.m g \cdot 100^{-1} g w . w .\right) ; \\
\text { a } p<0.001,{ }^{b} p<0.01 \text { and }\end{array}$ & $\begin{array}{l}0)+C 16: 0) \\
18: 0) /[(0.5 M \\
U F A / n 6 P U F \\
6+C 18: 3 n \\
+C 16: 0) \\
w . w .)+(0.0\end{array}$ & $\begin{array}{l}\text { (n6PUFA } \\
F A)+(0.5 n \\
)] ; \\
+C 20: 4 n 6\end{array}$ \\
\hline
\end{tabular}

High functional activities of EPA+DHA n3 LCPUFAs required the introduction of recommendations for their daily consumptions (approx. $500 \mathrm{mg} / \mathrm{day}$ ) [29]. Thus, the percentage level of these FAs were recalculate in $\mathrm{mg} \cdot 100^{-1} \mathrm{~g} \mathrm{w} . \mathrm{w}$. according to FAO/INFOOD Guidelines [30]. Due to higher skin TL content, this tissues contained significantly higher EPA+DHA n3 PUFA (0.786 $\left.\mathrm{g} \cdot 100^{-1} \mathrm{~g} \mathrm{w} . \mathrm{w} ., \quad p<0.001\right)$, compared to muscle $(0.521$ $\left.\mathrm{g} \cdot 100^{-1} \mathrm{~g} \mathrm{w} . \mathrm{w}\right)$. Despite the determined differences, both tissues provide from $105 \%$ (muscle) to $157 \%$ (skin) of the RDI. Moreover, regarding Commission Regulation (EU) No. 116/2010 [31] health claims for EPA and DHA food contents, the analyzed farmed African catfish could be defined as high in omega-3 PUFAs. Earlier investigation [20] showed higher EPA and DHA in skin and muscle tissues of farmed rainbow trout $\left(0.660-0.700 \mathrm{~g} \cdot 100^{-1} \mathrm{~g} \mathrm{w}\right.$.w.).

In this study the functional quality of catfish lipids were evaluated by several indices, as $\mathrm{AI}, \mathrm{TI}$ and $\mathrm{h} / \mathrm{H}$. Higher values of AI were determined for muscle tissue lipids, whereas skin lipids presented higher TI and $\mathrm{h} / \mathrm{H}$. Previous study of African catfish from Ijmuiden, Holland presented similar results for AI (0.57) and TI (0.33) in muscle tissues, but higher values for CSI [25]. Comparable data in literature for lipid quality indices of skin tissue was not found. The hypercholesterolaemic-atherogenic potential of catfish lipids was assessed through cholesterol/SFA index (CSI). In additions, calculated CSI is comparable with those calculated for farmed catfish (2.18) [25]. The low values of AI and TI indices for both tissues and moderate levels for CSI index found for the African catfish lipids point out their functional potential and preventive role against the risk of cardio-vascular diseases.

Other important lipid components are vitamin $\mathrm{E}$ and PUFA, which ratio $(0.5 \mathrm{mg}$ vitamin $\mathrm{E}$ per $\mathrm{g}$ PUFA) is used for fish lipid functional properties assessments (Table 3). Raederstorff et al. [32] supposed that vitamin E/PUFA > 0.5 is the minimum quantity of antioxidant (vitamin E) able to protect and metabolize dietary PUFAs, and the high ratio confirmed higher lipid quality. The observed results showed that both analyzed tissues have well balanced vitamin E/PUFA ratio, which increases their quality.

\section{Conclusions}

This study presented the first investigation of nutrition quality of farmed African catfish skin and muscle tissues lipids from Bulgarian markets. Observed results suggested that this species has valuable nutrition potential and physiological benefits to human health. Both analyzed tissues are very good sources of EPA+DHA omega-3 PUFAs. One hundred grams of raw skin or muscle can supply more than $100 \%$ of recommended daily intake of these FAs. African catfish tissues lipids were characterized by low content of cholesterol and high amounts of vitamin $\mathrm{D}_{3}$ and beta-carotene. The $\mathrm{n} 6 / \mathrm{n} 3$ and PUFA/SFA ratios proved to be advantageous, regardless of the tissue. The high content of unsaturated FAs, astaxanthin, vitamins $A$ and $D_{3}$ found in skin tissue show that this by-product could be successfully utilized in aquaculture and animal feed. In addition, the nutrition quality indices - low AI, TI and CSI; high $\mathrm{h} / \mathrm{H}$ and $\mathrm{mg}$ vitamin E/g PUFA highlight the relevance of the consumption of analyzed species in the prevention of different diseases, especially vascular disorders. Consequently, studied African catfish, with or without skin may constitute a healthy part of the everyday human diet.

Conflict of interest. Authors declared no conflict of interest.

\section{References}

[1]. FAO. The State of World Fisheries and Aquaculture 2016. Contributing to food security and nutrition for all, Rome 2016.

[2]. FAO-FISHSTAT, FAO Fisheries Department, Fishery Information, Data and Statistics Unit. FishstatJ, a Tool for Fishery Statistical Analysis, Release 2.0.0. Global Capture Fisheries Production 1950-2010, Global Aquaculture Production 1950-2010, Global Commodities Production and Trade 1978-2009, Rome 2012

[3]. M.C. Beveridge, S.H. Thilsted, M.J Phillips, M. Metian, M. Troell, S.J. Hall, Meeting the food and nutrition needs of the poor: the role of fish and the opportunities and challenges emerging 
from the rise of aquaculture, Journal of Fish Biology 83 (2013) 1067-1084.

[4]. N.E. Cruz Casallas, P.E. Cruz Casallas, H.S. Mahecha, (2012) 6799. Characterization of the nutritional quality of the meat in some species of catfish: a review, Revista Facultad Nacional de Agronomía, Medellín 65/2 (2012) 6799. 6809.

[5]. E. Uzunova and S. Zlatanova, A review of the fish introductions in Bulgarian freshwaters, Acta Ichthyologica et Piscatoria 37 (2007) 5561.

[6]. A. Merdzhanova, D.A. Dobreva, M. Stancheva, Quality evaluation of dietary lipid of channel catfish (Ictalurus Puntatus) from Bulgaria, Bulgarian Journal of Agricultural Science 21 (2015) 202-207.

[7]. E.G. Bligh, W.J. Dyer, Canadian Journal of Biochemistry and Physiology 37 (1959) 911.

[8]. BDS EN ISO 12966-2:2017. Animal and vegetable fats and oils - Gas chromatography of fatty acid methyl esters - Part 2: Preparation of methyl esters of fatty acids. $37 \mathrm{pp}$.

[9]. BDS EN ISO 12966-4:2015. Animal and vegetable fats and oils - Gas chromatography of fatty acid methyl esters - Part 4: Determination by capillary gas chromatography, $30 \mathrm{pp}$.

[10]. D.A. Dobreva, V. Panayotova, R. Stancheva, M. Stancheva, 112. Simultaneous HPLC determination of fat soluble vitamins, carotenoids and cholesterol in seaweed and mussel tissue, Bulgarian Chemical Communications 49 (2017) 112-117.

[11]. A. Simopoulos, Dietary omega-3 fatty acid deficiency and high fructose intake in the development of metabolic syndrome, brain metabolic abnormalities, and non-alcoholic fatty liver disease, Nutrients 5 (2013) 29012923.

[12]. T.L.V. Ulbricht, D.A.T. Southgate, Coronary heart disease: seven dietary factors, The Lancet 338 (1991) 985-992.

[13]. J. Santos-Silva, R.J.B. Bessa, F. Santos-Silva, Effect of genotype, feeding system and slaughter weight on the quality of light lambs: II. Fatty acid composition of meat, Livestock Production Science 77 (2002) 187-194

[14]. S.L. Connor, J.R. Gustafson, S.M. Artaud-Wild, D.P. Favell, C.J. Classick-Kohn et al. The cholesterol/saturated fat index an indication of the hypercholesterolemic and atherogenic potential of food, Lancet 327 (1986) 1229-1232.

[15]. P.J. Bechtel, J.M. Bland, K.L. Bett-Garber, C. Grimm, S. Brashear, S. Lloyd, M. Watson, J. Lea, Chemical and nutritional properties of channel and hybrid catfish byproducts, Food Science \& Nutrition 5 (2017) 981-988.

[16]. J. Luczynska, B. Paszczyk, M.J. Luczynski, Fatty acid profiles in marine and freshwater fish from fish markets in northeastern Poland, Archives of Polish Fisheries 22 (2014) 181-188

[17]. O.E. Taiwo, K. Usman, T.H. Ogono, R.O. Osoniyi, Proximate and lipid profile analysis of cultured and wild African catfish, Clarias gariepinus [Burchell], Ife Journal of Science 16 (2014) 133-142.

[18]. A.S.M.A Habib, P. Sarkar, Extraction and identification of PUFA from African Catfish (Clarias gariepinus) Skin, International Journal of Fisheries and Aquatic Studies 4 (2016) 312317.

[19]. A. Reboléa, S. Velascoa, M.L. Rodrígueza, J. Treviñoa, C. Alzuetaa, J.L. Tejedorb, L.T. Ortiza. Nutrient content in the muscle and skin of fillets from farmed rainbow trout (Oncorhynchus mykiss), Food Chemistry 174 (2015) 614-621.

[20]. D.A. Dobreva, A. Merdzhanova, L. Makedonski, Fat soluble nutrients and fatty acids in skin and fillet of farmed rainbow trout, Bulgarian Chemical Communications 49 (2017) 118-123.

[21]. J.K. Cho, Y.G. Jin, S.J. Rha, S.J. Kim, J.H. Hwang, Biochemical characteristics of four marine fish skins in Korea, Food Chemistry 159 (2014) 200-207.

[22]. R.S. Chapkin, V.A. Ziboh, C.L. Marcelo, J.J. Voorhees, Metabolism of essential fatty acids by human epidermal enzyme preparations: evidence of chain elongation, Journal of Lipid Research 27 (1986) 945-954.

[23]. K.L. Weaver, P. Ivester, J.A. Chilton, M.D. Wilson, P. Pandey, F.H. Chilton, The content of favorable and unfavorable polyunsaturated fatty acids found in commonly eaten fish., Journal of the American Dietetic Association 108 (2008) 1178-1185.

[24]. Ordinance №1/22.01.2018 on the physiological feeding of population, Ministry of Health, Bulgaria (in Bulgarian).

[25]. R. Rosa, N.M. Bandarra, M.L. Nunes, Nutritional quality of African catfish Clarias gariepinus (Burchell 1822): a positive criterion for the future development of the European production of Siluroidei, International journal of food science and technology 42 (2007) 342351.

[26]. G.T. Keleştemur, O.E. Çoban, Effects of The BCarotene on the Growth Performance and Skin Pigmentation of Rainbow Trout (Oncorhynchus mykiss, W. 1792), Journal of Fisheries Lives Product 4 (2016) 164-169.

[27]. S. Kaçar, M. Başhan, S.A. Oymak, Effect of seasonal variation on lipid and fatty acid profile in muscle tissue of male and female Silurus triostegus, Journal of Food Science and Technology 53 (2016) 2913-2922.

[28]. Department of Health. Nutritional aspects of cardiovascular disease: Health and social 
subjects, Report No 46 (1994) HMSO, London, 187 pp. 60.

[29]. EFSA Scientific opinion on the tolerable upper intake level of eicosapentaenoic acid (EPA), docosahexaenoic acid (DHA) and docosapentaenoic acid (DPA), EFSA Journal 10 (2012) p. 48.

[30]. FAO/INFOODS (2012). FAO/INFOODS Analytical food composition database version 1.0-AnFooD1.0. FAO, Rome http://www.fao.org/docrep/017/ap796e/ap796e. pdf

[31]. Commission Regulation (EU) No 116/2010 of 9 February 2010 amending Regulation (EC) No.
1924/2006 of the European Parliament and of the Council with regard to the list of nutrition claims.

[32]. D. Raederstorff, A. Wyss, P.C. Calder, P. Weber, M. Eggersdorfer, Vitamin E function and requirements in relation to PUFA, British Journal of Nutrition 114 (2015) 1113-1122.

Received: 01.05.2018

Received in revised form: 21.05 .2018

Accepted: 22.05 .2018 